\title{
Absorption conformations in the intercalation process of polycarboxylate ether based superplasticizers into montmorillonite clay
}

\author{
Pere Borralleras $^{a}$, Ignacio Segura ${ }^{\text {b,c,* }}$, Miguel A.G. Aranda ${ }^{\mathrm{d}}$, Antonio Aguado ${ }^{\mathrm{b}}$ \\ ${ }^{a}$ BASF Construction Chemicals Iberia, Ctra del Mig 219, E-08907 Hospitalet de Llobregat, Barcelona, Spain \\ ${ }^{\mathrm{b}}$ Department of Environmental and Civil Engineering, Universitat Politècnica de Catalunya-Barcelona Tech, Jordi Girona 1-3, C1, E-08034 Barcelona, Spain \\ ' Smart Engineering Ltd, Jordi Girona 1-3, ParcUPC - K2M, E-08034 Barcelona, Spain \\ ${ }^{\mathrm{d}}$ ALBA Synchrotron, Carrer de la Llum 2-26, E-08290, Cerdanyola del Vallès, Barcelona, Spain
}

\section{H I G H L I G H T S}

- Three absorption conformations are proposed for the intercalation of PCE polymers.

- The conformation taken by PCE (spatial arrangement) depends on both PCE and clay.

- Main controlling factors of PCEs are the side chain length and side chain density.

- Main controlling factors of the clay are the layer charge and particle morphology.

- PCE anionic charge only conditions one of the absorption conformations identified.

\section{A R T I C L E I N F O}

Article history:

Received 11 February 2019

Received in revised form 17 July 2019

Accepted 3 August 2019

Available online $\mathrm{xxxx}$

\section{Keywords:}

Polycarboxylate

Montmorillonite

Conformation

Intercalation

Absorption

Adsorption

\begin{abstract}
A B S T R A C T
The intercalation of polycarboxylate based superplasticizers (PCE) into montmorillonite clay (MNT) is arranged preferably by two types of absorption conformations: one-to-one conformation and bridging conformation. A third model named plugged conformation is described but it seems not appropriate to polymers having anionic charge and it would be possible only for very particular cases. The preferred conformation of absorption of the PCE polymer is determined by key properties of the polymer and the clay. For the polymer, the two main characteristics are the length of side chains and the side chain density. For the MNT clay, the mains properties are the layer charge and to a lesser extent the morphology of the clay particle. PCE anionic charge is not a determining factor for the absorption conformation but is a key factor for the earlier saturation of the interlaminar space by intercalation. Since many variables are interplaying simultaneously and complementarily, the interaction process between PCE polymers and MNT clays is very complex that deserves further studies.
\end{abstract}

(c) 2019 Elsevier Ltd. All rights reserved.

\section{Introduction}

Concrete technology made a breakthrough with the introduction of polycarboxylate based superplasticizers (PCE) at the end of the 90's [1]. Using PCE technology, it is possible to produce advanced concretes with improved fresh and mechanical properties [2], which are impossible to be achieved with the predecessor water-reducers admixtures. The advances made by PCE technology have been such to the point that new concrete types like

\footnotetext{
* Corresponding author at: Department of Enviromental and Civil Engineering, Universitat Politècnica de Catalunya-Barcelona Tech, Jordi Girona 1-3, C1, E-08034 Barcelona, Spain.

E-mail address: ignacio.segura@upc.edu (I. Segura).
}

self-compacting concrete and more recently ultra-high performance concrete $[3,4]$ are possible nowadays.

Despite all the positive contributions made by this new chemistry, there is a point pending of improvement for PCE based admixtures related to their compatibility with sands of limited quality. It is well known that sands containing small quantities $(<0.5 \%)$ of some specific clay types produce several affectation in the performance of PCE-based superplasticizers [5]. These clays are those that have swelling properties, such as smectitemontmorillonite clays [5-7], and they are able to totally inhibit the dispersing capacity of PCE polymers.

The interaction between clays and PCE polymers has been widely studied [8-16]. One of the most relevant conclusions from these investigations is the fact that montmorillonite clays (MNT) can absorb PCE polymers from the intercalation of their PEG/PEO 
based side chains. The understanding of the intercalation mechanism has been complemented thanks to the measurements of interlayer d-spacing using in situ XRPD analysis on fresh, unaltered clay pastes [17]. Using this methodology, it is demonstrated that the expansion of MNT clays produced by the intercalation of PCE side chains is larger than that deduced from the aforementioned studies and revels the true influence of the structure of PCE polymers in the affinity for intercalating inside montmorillonite clays, as presented by the authors in [18]. None of these observations can be clearly identified by the typical analytical method used to measure the interlayer d-spacing, which is based on XRPD analysis performed on centrifuged and dried clay pastes [17].

This work is part of our ongoing research effort to better understand the interaction of PCE with clays $[17,18]$ with the final aim to develop clay-resistant PCEs. In order to do so, the interaction between MNT and PCE polymers must be unravelled. The objective of this investigation is to complement the models for the intercalation mechanism on the basis of the information offered by the interlayer d-spacing measurements of MNT clay with in situ XRPD analysis, as well as to identify the main aspects and the determining factors that control and direct this process.

\section{Materials}

\subsection{Cement}

Cement used is a CEM I 52.5R. Table 1 presents oxide and mineral phase composition of the anhydrous cement (expressed in wt $\%$ ), determined by XRF (X-ray fluorescence) and Rietveld. The Blaine value reported in cement specifications is $4750 \mathrm{~cm}^{2} / \mathrm{g}$. The measured BET-specific surface is $1.6 \mathrm{~m}^{2} / \mathrm{g}$ and the particle size $\left(D_{50}\right)$, determined by laser diffraction is $10 \mu \mathrm{m}$. For the repro-

Table 1

Oxide composition and mineral phases of anhydrous cement and MNT clay used.

\begin{tabular}{|c|c|c|c|c|}
\hline & \multicolumn{2}{|c|}{ Oxide composition (wt\%) } & \multirow{2}{*}{\multicolumn{2}{|c|}{$\begin{array}{l}\text { Mineral phase composition } \\
\text { of cement (wt\%) }\end{array}$}} \\
\hline & Cement & MNT clay & & \\
\hline $\mathrm{SiO}_{2}$ & 19.60 & 63.12 & $\mathrm{C}_{3} \mathrm{~S}$ & 58.9 \\
\hline $\mathrm{Al}_{2} \mathrm{O}_{3}$ & 5.38 & 19.88 & $\mathrm{C}_{2} \mathrm{~S}$ & 14.0 \\
\hline $\mathrm{Fe}_{2} \mathrm{O}_{3}$ & 2.41 & 1.37 & $\mathrm{C}_{3} \mathrm{~A}$ total & 9.4 \\
\hline $\mathrm{CaO}$ & 65.29 & 2.24 & $\mathrm{C}_{3} \mathrm{~A}$ ort $/ \mathrm{cub}$ & $99 \%$ cubic \\
\hline $\mathrm{Na}_{2} \mathrm{O}$ & 0.05 & 3.43 & $\mathrm{C}_{4}(\mathrm{~A}, \mathrm{~F})$ & 5.7 \\
\hline $\mathrm{K}_{2} \mathrm{O}$ & 0.84 & 0.44 & $\mathrm{M}_{\mathrm{X}}\left(\mathrm{SO}_{4}\right)$ & 5.5 \\
\hline $\mathrm{MgO}$ & 0.82 & 2.33 & Total & 93.5 \\
\hline $\mathrm{SO}_{3}$ & 3.34 & - & & \\
\hline $\mathrm{TiO}_{2}$ & - & 0.01 & & \\
\hline $\mathrm{MnO}$ & - & 0.04 & & \\
\hline $\mathrm{NiO}$ & - & 0.06 & & \\
\hline LOI & 2.18 & 5.97 & & \\
\hline
\end{tabular}

ducibility of the experimental results obtained in this study, it should be stated that the amount of orthorhombic $C_{3} A$ of cement is very low, while its sulphate content is high. This feature is important when conditioning the levels of adsorption of the admixtures [19].

\subsection{Sodium montmorillonite clay (Na-MNT)}

The clay used in this investigation is a powder sodium montmorillonite (Na-MNT) sample. Oxide composition by XRF is shown in Table 1 (expressed in wt\%). The BET-specific surface is measured at $49.5 \mathrm{~m}^{2} / \mathrm{g}$ (average of two measurements: $46.1 \mathrm{~m}^{2} / \mathrm{g}$ and $52.8 \mathrm{~m}^{2}$ / $\mathrm{g})$ and the average particle size $\left(D_{50}\right)$, determined by laser diffraction, is $7.4 \mu \mathrm{m}$. A d $\mathrm{d}_{001}$ value of $12.3 \AA$ is deduced from its $2 \theta$ position at $7.2^{\circ}$ in XRPD analysis on raw (dry) clay powder. This value is typical for Na-MNT clays with one $\mathrm{H}_{2} \mathrm{O}$ molecule layer inside the interlaminar space [11,17]. Some impurities are identified: $4.8 \mathrm{wt} \%$ of quartz and $3.3 \mathrm{wt} \%$ of calcite, which explains the loss-on-ignition (LOI) value and the amount of $\mathrm{CaO}$ identified. Before its use, the powder clay is dried at $70^{\circ} \mathrm{C}$ for $48 \mathrm{~h}$ to remove its residual moisture.

\subsection{Water-reducer/superplasticizer polymers}

Two different pure polycarboxylate ether (PCE) polymers presented in aqueous solution are used (PCE-1100 and PCE-5800). Complementary to the PCE polymers, two PCE polymers blocked for adsorption (XPE-1100 and XPE-5800) are used in this investigation. The blockage of the free carboxylic groups (which are the promoters for the surface adsorption) is obtained by esterification of the carboxylic monomers of the PCE backbone and by the direct polymerization of hydrolysable monomers, which allows to disable the effective anionic charge of the polymer [20]. By blocking the free carboxylic groups, XPE polymers cannot be adsorbed until the esterified terminals are released by hydrolysis (normally, from 30 to 60 minutes after mixing). Therefore, since the adsorption at an initial time is not possible, the blocked PCE polymers (XPE) are not able to generate any fluidification effect until the esterified carboxylic groups are not unblocked by hydrolysis. Table 2 presents the characteristics of the PCE and XPE polymers used. The side chain frequency and the side chain density are calculated from the PCE anionic charge, determined by titration with $\mathrm{KOH} \mathrm{[18].}$

Complementary to the PCE and XPE polymers, a $60 \mathrm{wt} \%$ solution of a linear sodium polymethacrylate polymer (PMA) with a molecular weight of $8000 \mathrm{~g} / \mathrm{mol}$ and a calcium salt of $\beta$-naftalensulfo nate-formaldehyde polymer (Ca-BNS) at $40 \mathrm{wt} \%$ concentration are used for comparison purposes. All admixtures are tested at an equal solid concentration of $40 \mathrm{wt} \%$, prepared by dilution with distilled water.

Table 2

Chemical structure and composition of PCE polymers.

\begin{tabular}{|c|c|c|c|c|c|}
\hline \multicolumn{2}{|l|}{ Parameter } & PCE-1100 & PCE-5800 & XPE-1100 & XPE-5800 \\
\hline \multicolumn{2}{|c|}{ Solid concentration (wt\%) } & $50.3 \%$ & $46.4 \%$ & $45.7 \%$ & $42.2 \%$ \\
\hline \multicolumn{2}{|c|}{ Main backbone monomer } & Acrylic & Maleic & Acrylate-ester & \\
\hline \multicolumn{2}{|c|}{ Anionic charge (mg KOH/g PCE) } & 99 & 44 & - & - \\
\hline \multirow[t]{3}{*}{ Side chains } & Type & IPEG & VPEG & IPEG & VPEG \\
\hline & mol EO/side chain & 25 & 132 & 25 & 132 \\
\hline & $\mathrm{Mw}(\mathrm{g} / \mathrm{mol})$ & 1100 & 5800 & 1100 & 5800 \\
\hline \multicolumn{2}{|c|}{$\begin{array}{l}\text { Side chain frequency } \\
\text { (molar ratio side chain/backbone) }\end{array}$} & 0.31 & 0.29 & Not determined & \\
\hline \multicolumn{2}{|c|}{$\begin{array}{l}\text { Side chain density } \\
\quad(\text { mol EO } \cdot \text { side chain frequency })\end{array}$} & 7.8 & 38.3 & & \\
\hline
\end{tabular}




\subsection{Non-ionic polymers}

Table 3 presents the four selected non-ionic, non-water-reducer polymers without any dispersing property (MPEG-500, PEO-4000 and APEO-440), used to support in the interpretation of the interaction conformations of the PCE polymers.

The selection of non-ionic polymers is made to compare linear polymers of equal length but different polarity and of equal polarity but different length that help the interpretation of the results. A comparison of the polymer length fof MPEG-500, APEO-440 and PEO-4000 is given in Fig. 1.

One can observe that both MPEG-500 and APEO-440 are linear polymers based on a polyethoxylated (PEO/PEG) polar chain of equivalent length, whose composition is identical to that of the PCE side chains. However, MPEG-500 and APEO-440 present important differences in the polarity of the base terminal that lead to totally different behaviours. The methyl terminal of MPEG-500 is non-polar, but it is small enough to allow the 11 EO (ethylene oxide) mol composing the linear chain to make the polymer totally water-soluble and stable in a polar media. Conversely, the nonylphenol base terminal of APEO-440 is very hydrophobic to the point that its solubility in water is only partial, despite of the $10 \mathrm{EO}$ mol of the linear chain. It means that the APEO-440 polymer acquires micellar arrangements in polar media such as water. The PEO-4000 is a linear polymer exclusively based on condensed units of ethylene oxide. Its composition is identical to MPEG-500 but its total length is up to 8 times longer.

\subsection{Synthetic cement pore solution}

All clay pastes are produced using synthetic cement pore solution as the liquid phase. The solution is prepared by dissolving $14.3 \mathrm{~g}$ of $\mathrm{Na}_{2} \mathrm{SO}_{4}, 3.05 \mathrm{~g}$ of $\mathrm{NaOH}$ and $3.00 \mathrm{~g}$ of $\mathrm{Ca}(\mathrm{OH})_{2}$ in 1 litre of distilled freshly-boiled water (equivalent to $0.157 \mathrm{~mol} / \mathrm{l}$ of $\mathrm{OH}^{-}, 0.278 \mathrm{~mol} / \mathrm{l}$ of $\mathrm{Na}^{+}, 0.100 \mathrm{~mol} / \mathrm{l}$ of $\mathrm{SO}_{4}^{2-}$ and $0.040 \mathrm{~mol} / \mathrm{l}$ of $\mathrm{Ca}^{2+}$ concentration). The synthetic cement pore solution is always freshly prepared to avoid carbonation.

\section{Experimental methods}

\subsection{Preparation of cement and clay pastes}

Clay pastes are prepared at $22^{\circ} \mathrm{C}$ by dispersing powdered $\mathrm{Na}$ MNT clay in the synthetic cement pore solution at $17 \mathrm{wt} \%$ concentration. The mixing process is done using a vertical shaft mixer equipped with a helical head, moving at $600 \mathrm{rpm}$. The total mixing time is four minutes, during which the admixture is added at the required dosage after the one-minute mark. Cement pastes are prepared following the same procedure as clay pastes but dispersing the cement with tap water at $22{ }^{\circ} \mathrm{C}$.

\subsection{Measurement of paste fluidity}

Fluidity of cement and clay pastes is determined by the measurement of paste flow in the mini-slump test. The test uses a metallic truncated mini-cone that is $55 \mathrm{~mm}$ high, with an upper diameter of $19 \mathrm{~mm}$ and a lower diameter of $38 \mathrm{~mm}$. The minicone is arranged on a flat, clean glass surface. It is filled with fresh paste and then compacted with a crystal rebar to evacuate trapped air. The mini-cone is then lifted to let the paste to flow onto the glass surface until the paste reaches maximum spread. The paste spread (paste flow, expressed in $\mathrm{mm}$ ) is measured in two perpendicular directions and the average value is taken. This test is widely used to evaluate the fluidity of fresh cementitious pastes.

\subsection{Sorption of polymers on cement and clay}

The total sorbed fraction of organic polymers (including the adsorbed and absorbed fraction) on both cement and clay is measured by determination of the total organic carbon (TOC) with a Shimadzu testing equipment. Freshly prepared pastes containing organic polymer are diluted with Millipore water and mixed for 30 seconds to facilitate the phase separation. Clay or cement suspensions are separated by centrifugation at $15,000 \mathrm{rpm}$ for $10 \mathrm{~min}-$ utes and the obtained liquid phase is filtrated with a $0.45 \mu \mathrm{m}$

Table 3

Structure and composition of non-ionic polymers.

\begin{tabular}{|c|c|c|c|c|}
\hline Non-ionic polymer & Composition & $\mathrm{Mw}(\mathrm{g} / \mathrm{mol})$ & Structure & Calculated length $(\AA)$ \\
\hline MPEG-500 & Methoxy-polyethylene glycol & 500 & Linear & 37 \\
\hline PEO-4000 & Polyethylene oxide (91 EO) & 4000 & Linear & 296 \\
\hline APEO-440 & 10-EO Ethoxylated nonylphenol & 660 & Linear & 41 \\
\hline
\end{tabular}

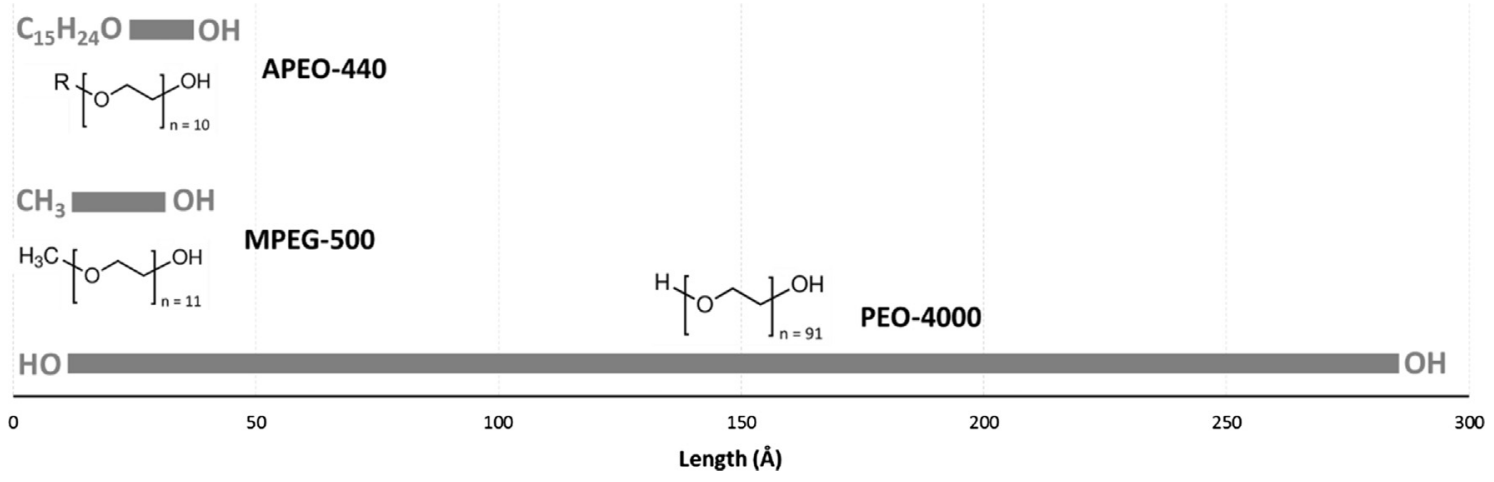

Fig. 1. Scaled representation of the non-ionic polymers' length. 
syringe Nylon filter. The final filtrate is acidified with concentrated $\mathrm{HCl}$ to remove inorganic carbon and is then submitted for TOC analysis by combustion at $900{ }^{\circ} \mathrm{C}$. Previously, calibration lines of each polymer were prepared by recording the TOC value of three different concentrations of polymers. The sorbed fraction of PCE is calculated by interpolation between the calibration lines from the difference of the total PCE dosage added and the non-sorbed fraction of PCE identified in the filtrate. Results are expressed as a percentage of sorption of the total PCE dosage and/or in sorbed mg of PCE per gram of cement or clay.

\subsection{In situ XRPD patterns of fresh clay pastes}

XRPD patterns for fresh, unaltered clay pastes are obtained following the experimental procedures previously described in [17]. In brief, in-situ XRPD analysis of fresh, unaltered clay pastes are performed using an MSPD diffractometer using synchrotron radiation at ALBA Synchrotron (Barcelona) and with a PANalytical X'Pert PRO MPD Cu K $\alpha$ lab diffractometer $(\lambda=1.5418 \AA)$. As some diffraction peaks display asymmetry, the peak positions were not determined by fitting the suitable range of the profiles to symmetric functions. The diffraction peak positions are determined from the maxima of the intensities.

\section{Results and discussion}

\subsection{Dispersing capacity of water-reducer polymers in cement and clay} pastes

The generation of initial fluidity produced by different dosages of the water-reducer polymers is presented in Fig. 2. The results of paste flow measured in cement pastes at $\mathrm{w} / \mathrm{c}$ ratio 0.26 and in clay pastes at $17 \%$ wt. concentration are presented in Fig. 2(a, b), respectively.

The results shown in Fig. 2(a) confirms that the dispersing capacity of the PCE polymers in cement paste is much superior than those of Ca-BNS and PMA water-reducers, as expected $[8,21,22]$. Nevertheless, this trend is reversed in the clay pastes (see Fig. 2(b)), observing that the dispersing capacity of the PCE polymers results severally altered as consequence of the capacity of MNT clays to inhibit the dispersing performance of PCE polymers [11]. From the fluidity curves of the PCE polymers in clay pastes presented in Fig. 2(b), it is detected that the first additions of PCE (from $0 \%$ to $100 \%$ dosage) produce a flocculation effect, despite the addition of a dispersing agent, and that a high dosage of PCE is required to start generating positive fluidification. Conversely, the behaviour of Ca-BNS and PMA water-reducers in the paste flow evolution of clay pastes is not affected in the same magnitude than PCE polymers. On the one hand, the initial flocculation phase is not observed with Ca-BNS and PMA, and on the other, the generation of fluidity at equivalent dosage is higher than that of PCE polymers. Therefore, despite demanding higher dosages than the PCE polymers in the cement pastes to achieve the same paste flow level, the affectation on the dispersing performance of Ca-BNS and PMA in clay pastes is by far not comparable to that of PCE polymers. It evidences that both Ca-BNS and PMA waterreducer polymers are almost clay insensitive $[8,13,23,24]$.

\subsection{Expansion of Na-MNT clay by in situ XRPD on fresh, unaltered clay pastes}

In-situ XRPD analysis on fresh, unaltered clay pastes evaluates the evolution of the interlaminar space dimension $\left(\mathrm{d}_{001}\right)$ for Na-MNT clay produced by different dosages of PCE polymers. Synchrotron XRPD patterns in Kratky format are presented in Fig. 3(a, b) for PCE-1100 and PCE-5800, respectively. XRPD patterns for Na-MNT pastes with Ca-BNS and PMA are not performed because both polymers do not produce any variation in the interlayer d-spacing of the clay, since they are not absorbed into MNT clays at any dosage $[8,13]$.

The initial peak at $18.5 \AA$ (marked as Peak 3 in Fig. 3) for the clay paste without any polymer is compatible to 3 water molecules absorbed in the interlayer region [25]. From this initial d-spacing, further clay expansion is produced at each addition of PCE polymer, referred as Peak 1 in Fig. 3. Peak 1 is not present in clay pastes without PCE polymer and it is being progressively displaced to lower angles when PCE dosage increases. According to the previous work of the authors [18], the larger increase of d-spacing observed with PCE-5800 is consequence of its longer side chains, larger than that of PCE-1100 polymer. Additionally, Peak 2 is attributed to clay specimens originated by exfoliation of the dispersed clay particles, having diverse levels of intercalation which are coexisting with the main clay specimen with the largest expansion. From the different position and intensity of the peaks, it is confirmed that clay exfoliation induced by PCE-5800 is significantly more accused than of PCE-1100 due to the higher side chain density and the longer side chains. From the multiple intercalation model of side chains proposed in [17], it is possible to estimate the number of water
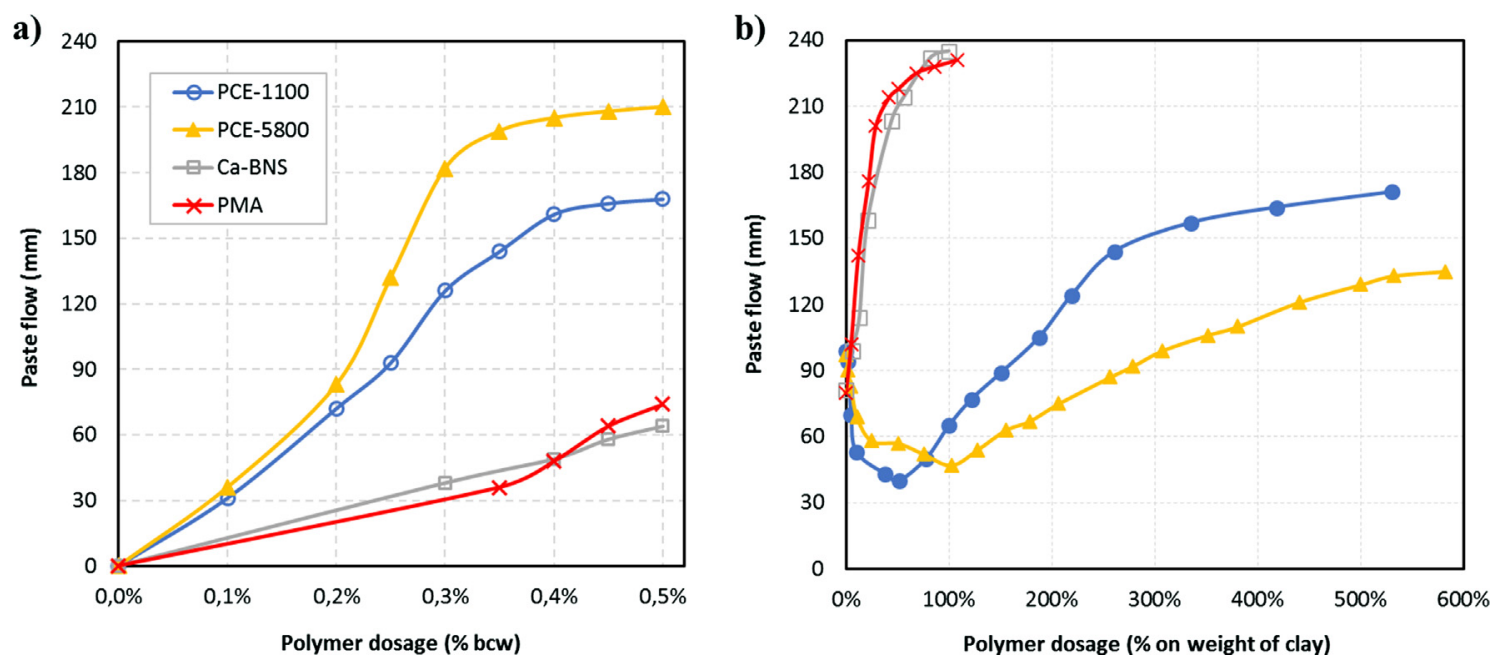

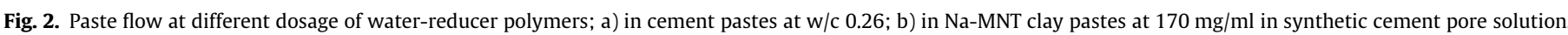


a)

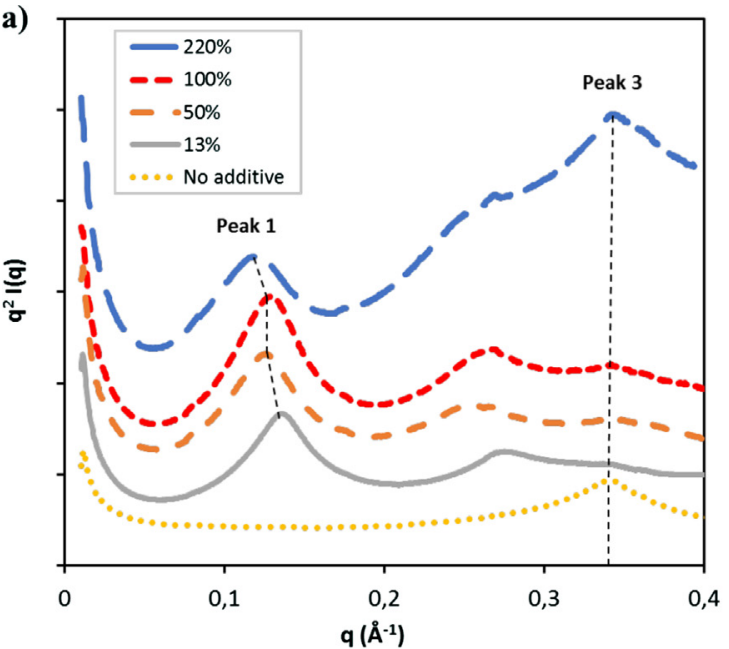

b)

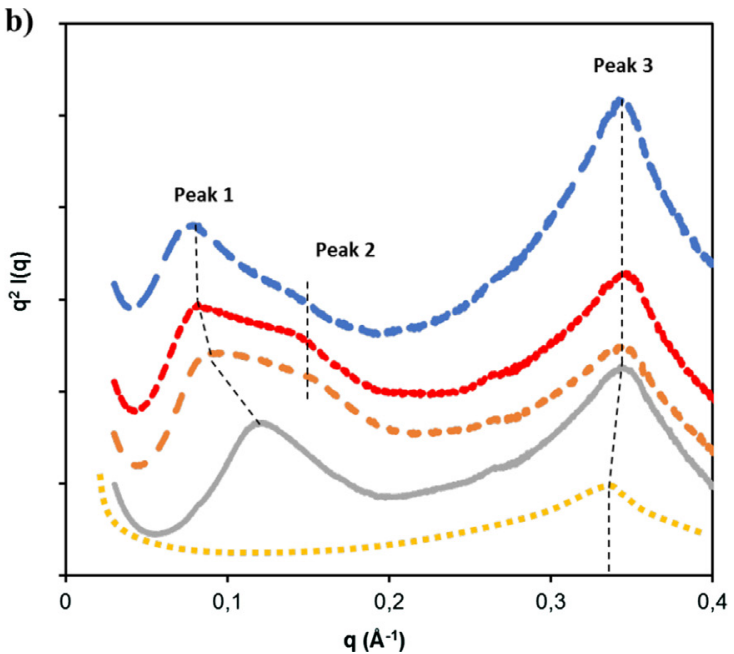

Fig. 3. In situ synchrotron XRPD patterns of fresh, unaltered clay pastes as increasing dosage of PCE polymers; a) PCE-1100; b) PCE-5800.

molecules layers and the number of side chains layers and intercalated for each result of $d$-spacing (intercalation degree, $n_{\text {PEG }}$ ). Fig. 4 displays the evolution of the maximum d-spacing (Peak 1 ) at each dosage of PCE polymers and its correspondence with the number of PCE side chains intercalated.

Fig. 4 shows that major d-spacing changes are produced at the initial additions of PCE while at higher dosage the d-spacing variations become more moderated and tend to stabilization. By comparing d-spacing evolution against fluidity curves of clay pastes presented in Fig. 2(b) for both PCE polymers, it can be stated that the dosage range when flocculation phase is observed matches with the PCE dosages where the biggest d-spacing variations are observed. Additionally, the threshold dosage of PCE polymer in clay pastes from which the positive generation of fluidity starts (see Fig. 2(b)) is related with similar dosages at which the d-spacing variations stabilize. According to the mechanism proposed by [17] based on the multiple intercalation of PCE side chains into the interlaminar space of MNT, the successive increase of number of side chains intercalated ( $n_{P E G}$ ) forces the intercalation of one additional layer of water molecules to coordinate the PEO/PEG chains in the way that $\mathrm{n}_{\mathrm{H} 20}=\mathrm{n}_{\mathrm{PEG}}+1$. Therefore, the experimented reduction of fluidity observed in clay pastes at the initial dosages of
PCE could be justified by the additional water uptake of the clay promoted by the successive intercalation of side chains. Fig. 5(a, b) illustrates the changes produced in the number of absorbed water layers into the interlaminar space of MNT when PCE side chains are intercalated.

From the initial conformation presented in Fig. 5(a) where 3 water layers are absorbed in the interlaminar space of MNT clay, the intercalation of 8 units of PCE side chains forces to increase the number of absorbed water layers up to 9 to coordinate each side chain intercalated [17]. Since the additional water molecules absorbed are captured from the solution, it is plausible to state that this large water uptake promoted by the PCE intercalation is responsible for the initial flocculation observed in clay pastes at the early additions of PCE polymers, and this loss of fluidity is not stabilized until the interlaminar space of MNT clay is not saturated [18] and likely exfoliated. From this hypothesis, the flocculation phase should be more pronounced for PCE polymers capable to produce higher intercalation levels. It is in agreement with the fluidity curves shown in Fig. 2(b), since the dosage range where flocculation is being produced is larger for PCE-5800 polymer having longer side chains and higher side chain density than for PCE1100 with shorter side chains and lower side chain density.

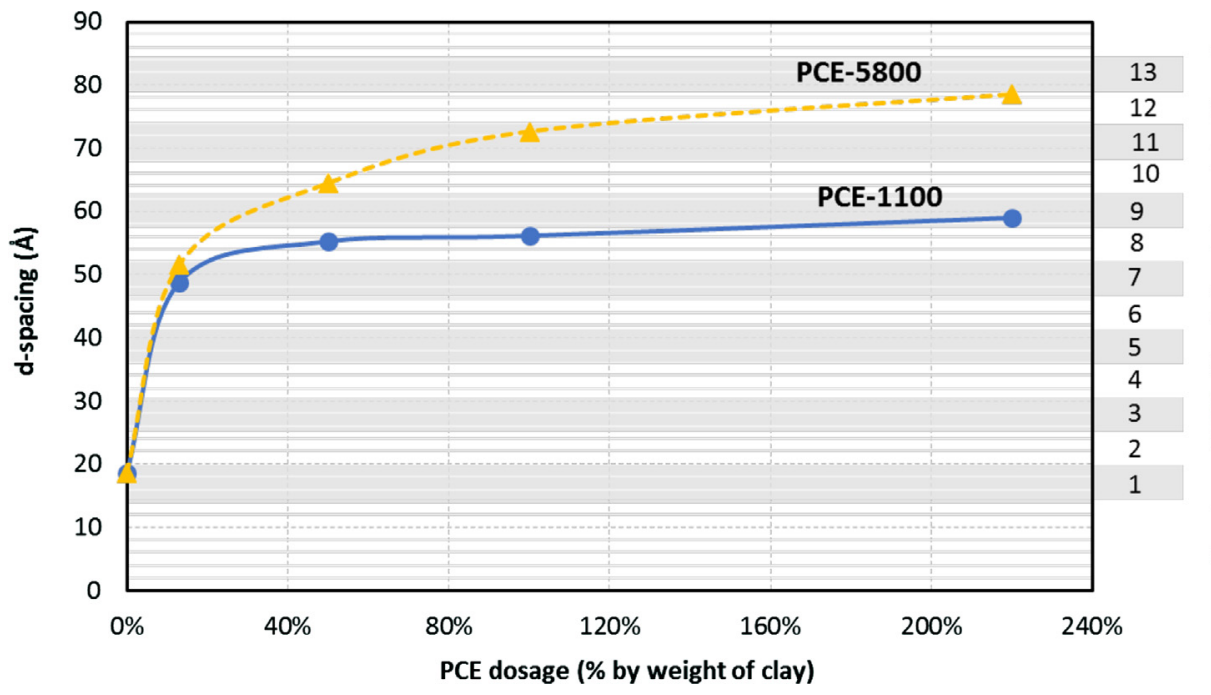

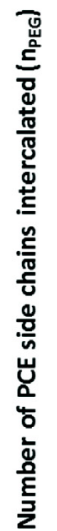

Fig. 4. Maximum d-spacing and intercalation degree at each dosage of PCE polymers. 
a)

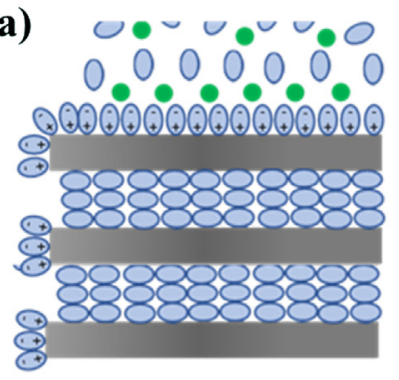

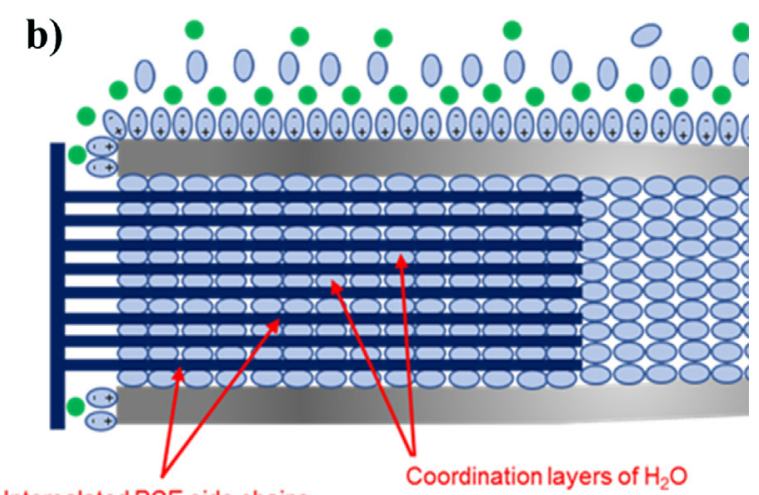

Intercalated PCE side chains

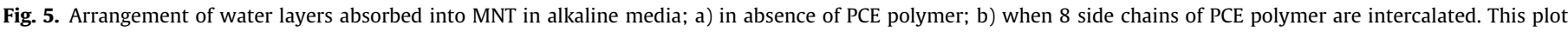
highlights the enhanced water demand of PCE-intercalated MNT,

The consequences from the intercalation of side chains on the distribution of the interlayer cations is not fully understood yet. It is likely that some of these interlayer cations are exchanged by the intercalated PCE side chain, so being removed from clay interlaminar space. Nevertheless, various studies [26-28] propose models for the cation redistribution forced by the intercalation of organic polymers since it is confirmed that an important part of the interlayer cations remains inside the interlaminar space after the intercalation of lineal polyethylene glycols (PEG), and that these cations are not directly coordinated by the oxygen atoms of PEG chains. Therefore, it is feasible to speculate that some of the interlayer cations are displaced by the intercalation towards the innermost part of the interlayer region thus creating a mismatch in the net charge balance. At this point, a local accumulation of positive charges could be created in the most inner region of the interlaminar space while in the locations closer to the periphery edge-area (from where side chains are intercalated) the repulsion between clay plates is increased due to the lack of cations balancing (at least partially) the permanent charges of the clay plates (layer charge). The proposed model of innermost cation displacement is aligned with the poor layer stacking order and turbostratic disorder of stacked layers produced along the $c$-axis $[25,29]$ and observed in the XRPD patterns of MNT clay pastes when PEG/
PEO side chains are intercalated [16,18]. Fig. 6 illustrates the proposed model of innermost cation displacement.

The loss of stacking order (being the preliminary step to clay delamination) and the formation of new exfoliated clay specimens with lower number of stacked plates (along $c$ axis) generate broader and asymmetric peaks in the XRPD patterns [29,30], as it can be clearly appreciated in Fig. 3. Thus, according to the model presented in Fig. 6, the longer the side chains the wider the region of repulsion generated between clay plates. It is also in agreement with the fact that PCE polymers with longer side chains are capable to induce higher levels of clay exfoliation [18]. Clay exfoliation generates new additional basal surface $[24,31,32]$ being comparable to an effective reduction of PCE dosage in terms of fluidity generation and thus may be a plausible theory to explain why PCE polymers with such structure induce higher clay exfoliation.

This model, together with the hypothesis for the additional water uptake of MNT clay promoted by the intercalation of PCE side chains, is in agreement with the differences observed in the previous Fig. 2(b) in regards of the fluidity evolution of clay pastes between PCE-1100 and PCE-5800, where the polymer having longer side chains contradictory denotes lower fluidification capacity at all dosages than PCE-1100 polymer, based on shorter side chains and reduced side chain density.

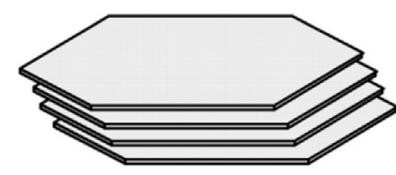

Organized layered structure

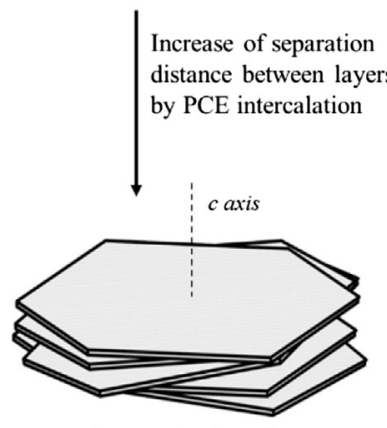

Turbostratic disorder

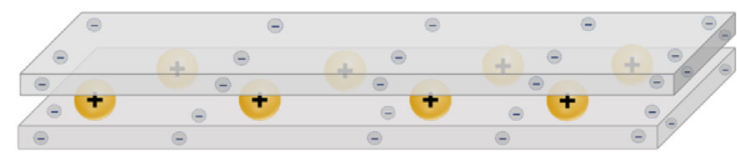

Displacement of interlayer cations to innermost region promoted by PCE side chain intercalation from plate edge borders

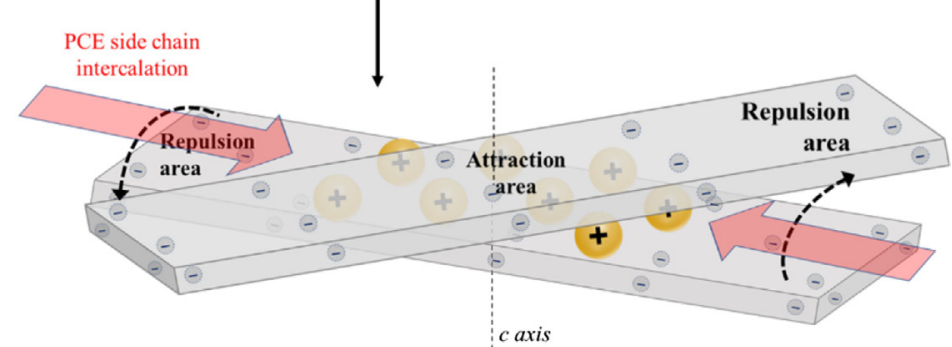

Fig. 6. Illustration of the innermost cation displacement model induced by the intercalation of PCE side chains and its alignment with the loss of layer stacking order. 
4.3. Effects on the fluidity of cement and clay pastes produced by XPE polymers (esterified PCE) and by the non-ionic polymers

The variations of fluidity of cement pastes at w/c 0.45 and of clay pastes at $170 \mathrm{mg} / \mathrm{ml}$ concentration produced by the addition of XPE-1100 and XPE-5800 blocked PCE polymers and by the addition of the non-ionic polymers (MPEG-500, PEO-4000 and APEO440 ) are presented in Fig. 7. Dosage used for all polymers is $0.3 \%$ on cement weight for cement pastes and $50 \%$ on clay weight for clay pastes. The results of paste flow obtained for these polymers are compared against the paste fluidity generated by the waterreducer polymers at the same dosage (from Fig. 2(a)). For both type of pastes, the changes in fluidity are represented in relative terms, referenced to the fluidity value of cement and clay paste without admixture, being $61 \mathrm{~mm}$ for cement paste and $99 \mathrm{~mm}$ for clay paste. In these terms, a relative value of 0 means no variation of paste flow, positive values mean increase of paste flow and the value -1 means the complete loss of fluidity.

As expected, while fluidity of cement pastes is increased by the addition of PCE-1100, PCE-5800, Ca-BNS and PMA (so all waterreducer polymers), the esterified PCE polymers XPE-1100 and XPE-5800 do not produce any significant variation in the paste flow. The same behaviour is observed in cement paste for all the non-ionic polymers. In clay pastes, the addition of $50 \%$ of PCE1100 and PCE-5800 generates a reduction of fluidity, so reproducing the same flocculation effect already presented in Fig. 2(b), which is not observed for Ca-BNS and PMA water-reducers since an increase of fluidity is registered for both polymers in clay pastes.

The reduction of fluidity observed for the non-ionic polymers in clay pastes is of particular interest since they do not produce any variation of fluidity in cement pastes. The most pronounced reduction of fluidity observed in the clay pastes for all polymers tested corresponds to APEO-440. Both XPE-1100 and XPE-5800 esterified polycarboxylates also experience some fluidity loss but of lower level than those of PCE polymers. It is noticed that the fluidity reduction of XPE-1100 is higher than of XPE-5800, so keeping the same trend than observed in the case of PCE polymers in clay pastes, where reduction of fluidity of PCE-1100 is more pronounced than of PCE-5800 and aligned with the length of the side chains of each polymer. A similar trend is observed for MPEG-500 and PEO-4000 in relation to PCE-1100 and PCE-5800, but in this case the differences in paste flow between both polyglycols are more pronounced. The fluidity loss produced by MPEG-500 is of higher magnitude, being comparable to the fluidity reduction for PCE polymers. Conversely, the reduction of fluidity for PEO-4000 it is 3 times lower than for MPEG-500 and comparable to XPE5800 blocked PCE.

This behaviour, together with the observations from Fig. 2(b), suggests that the longer the side chains the lower the absolute fluidity reduction at the flocculation phase but prolonging the flocculation effect along the dosage range required to reactivate the positive generation of fluidity. Therefore, it is an indicator that some differences in the intercalation mechanism must take place as a function of the length of PCE side chains.

\subsection{Sorption of polymers on cement and clay}

Experimental results of sorption for water-reducer polymers and for the non-ionic polymers on cement and on clay are presented in Fig. 8(a, b) respectively. As previously described, polymer dosage used is $0.3 \%$ in cement pastes and $50 \%$ in clay pastes. The results of sorption on cement are in accordance with the typical sorption values reported in literature [33-38] and with the fluidity results presented in Fig. 7, since the reduced sorption is correlated with the lower generation of fluidity and vice versa. Nevertheless, this correlation is not met in the case of clay pastes, except for CaBNS and PMA. All other polymers present high sorption rates on Na-MNT clay but it is not translated into additional generation of fluidity. Therefore, as it already known in the case of MPEG-500 and PEO-4000, all these polymers are susceptible to being absorbed by the clay in a comparable way than PCE polymers since sorption results from TOC analysis do not distinguish between adsorbed polymer on the surface and absorbed polymer by intercalation.

\subsection{XRPD patterns for XPE (blocked PCE) and non-ionic polymers}

In-situ XRPD on fresh, unaltered clay pastes measures the changes in the interlayer d-spacing of the clay produced by the addition of a 50\% dosage of XPE-1100, XPE-5800 and the nonionic polymers MPEG-500, PEO-4000, APEO-440. XRPD patterns obtained are displayed in Fig. 9(a, b). For the sake of comparison, Fig. 9(a) includes the XRPD pattern of the PCE-1100 polymer.

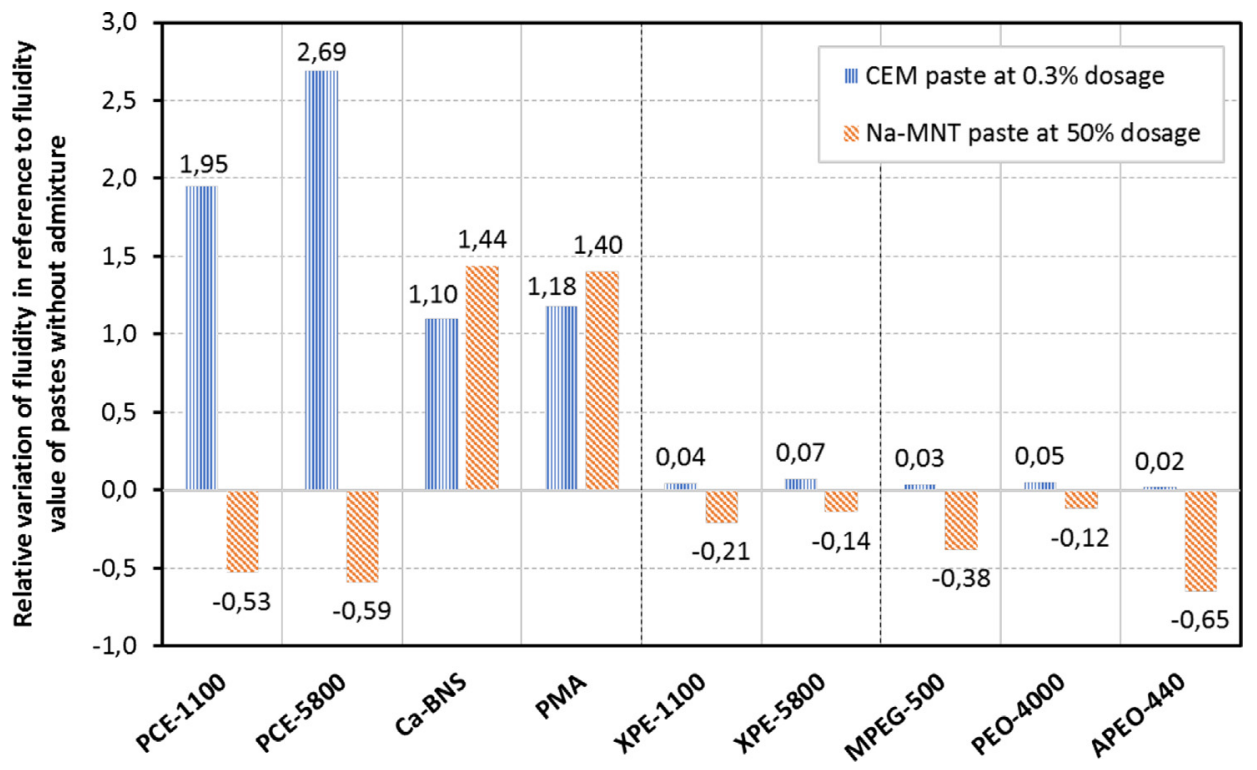

Fig. 7. Relative variation of fluidity produced by $0.3 \%$ dosage in cement paste and by $50 \%$ dosage in clay paste of polymers tested. 
a)

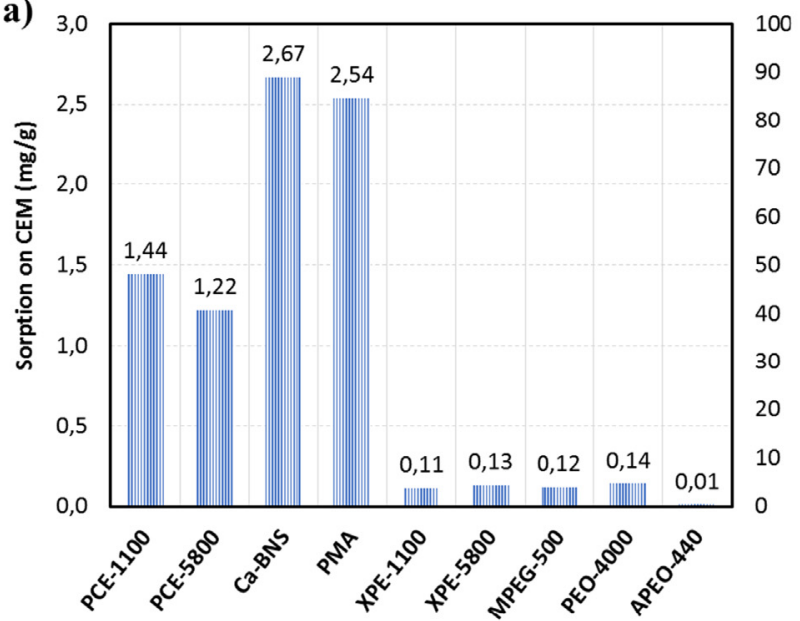

b)

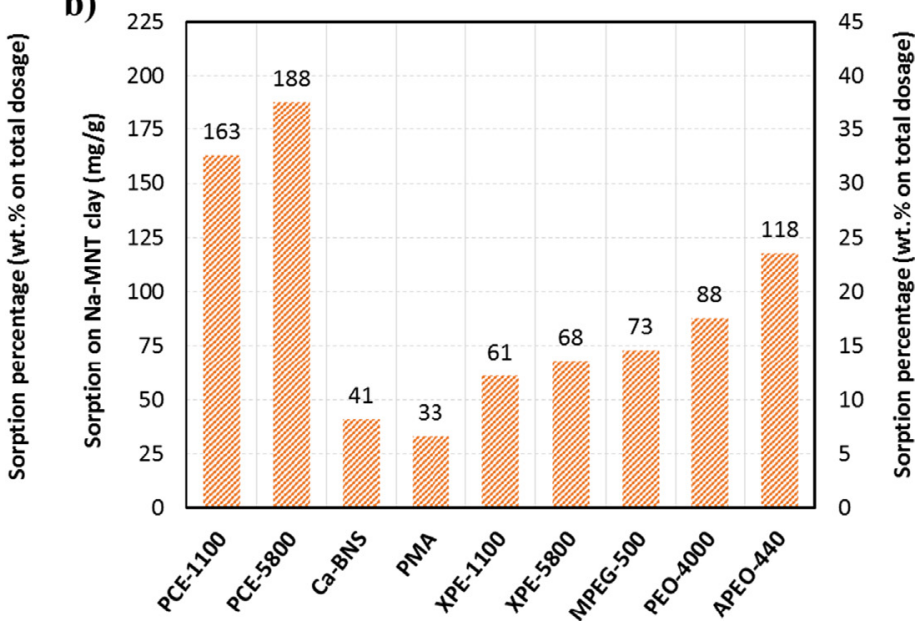

Fig. 8. Sorbed amounts of polymer on; a) cement; b) Na-MNT clay.

a)

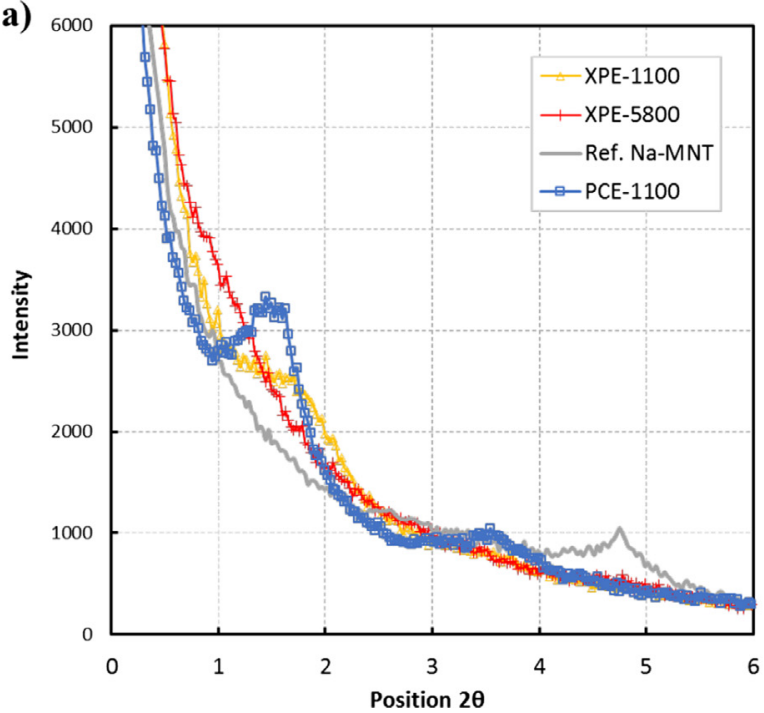

b)

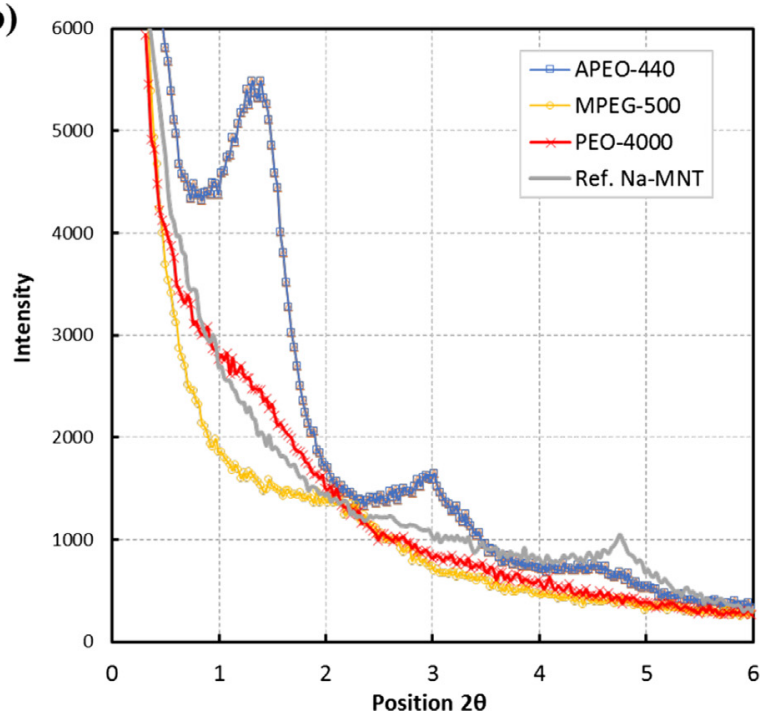

Fig. 9. In-situ XRPD patterns for fresh, unaltered, clay pastes with 50\% dosage of; a) XPE esterified polycarboxylates and PCE-1100; b) non-ionic polymers.

The interlayer $\mathrm{d}$-spacing associated to the main peaks identified in the XPRD patterns of Fig. 9 and the degree of intercalation ( $\left.n_{P E G}\right)$ calculated according to [17] are presented in Table 4, excluding the equivalent peaks by order of reflection. For the case of XPE-5800, the position of the main peak is hardly distinguishable. This may be due to the required sample preparation when using a $\mathrm{Cu} \mathrm{K \alpha}$ lab diffractometer for in situ XRPD, which is not needed when in situ XRPD analysis are performed with Synchrotron light. As observed in [17], Synchrotron light offers a much higher resolution than $\mathrm{Cu} \mathrm{K} \alpha$ lab diffractometer. The d-spacing and $\mathrm{n}_{\mathrm{PEG}}$ values displayed in Table 4 for PCE- 1100 and PCE-5800 are extracted from the XRPD patterns presented in Fig. 3.

The net clay expansion (obtained by subtracting $9.6 \AA$ from the results of d-spacing, being $9.6 \AA$ the typical thickness of the T-O-T

Table 4

Summary of d-spacing values and $\mathrm{n}_{\mathrm{PEG}}$ for main diffraction peaks in Fig. 10.

\begin{tabular}{|c|c|c|c|c|c|c|}
\hline & \multicolumn{3}{|c|}{ d-spacing $(\AA)$} & \multicolumn{3}{|c|}{$\mathrm{n}_{\text {PEG }}$} \\
\hline XPE-1100 & 49.6 & 42.7 & - & 7 & 6 & - \\
\hline XPE-5800 & 49.6 & - & 18.5 & 7 & - & 0 \\
\hline MPEG-500 & 46.3 & - & 18.5 & 6 & - & 0 \\
\hline PEO-4000 & 63.6 & $\begin{array}{l}44.9 \\
42.3\end{array}$ & & 10 & 6 & - \\
\hline APEO-440 & 64.5 & - & 18.6 & 10 & - & 0 \\
\hline POE-900 & - & - & 18.6 & - & - & 0 \\
\hline PCE-1100 & 55.2 & - & 18.3 & 8 & - & 1 \\
\hline PCE-5800 & 64.4 & 41.7 & 18.4 & 10 & 6 & 1 \\
\hline
\end{tabular}




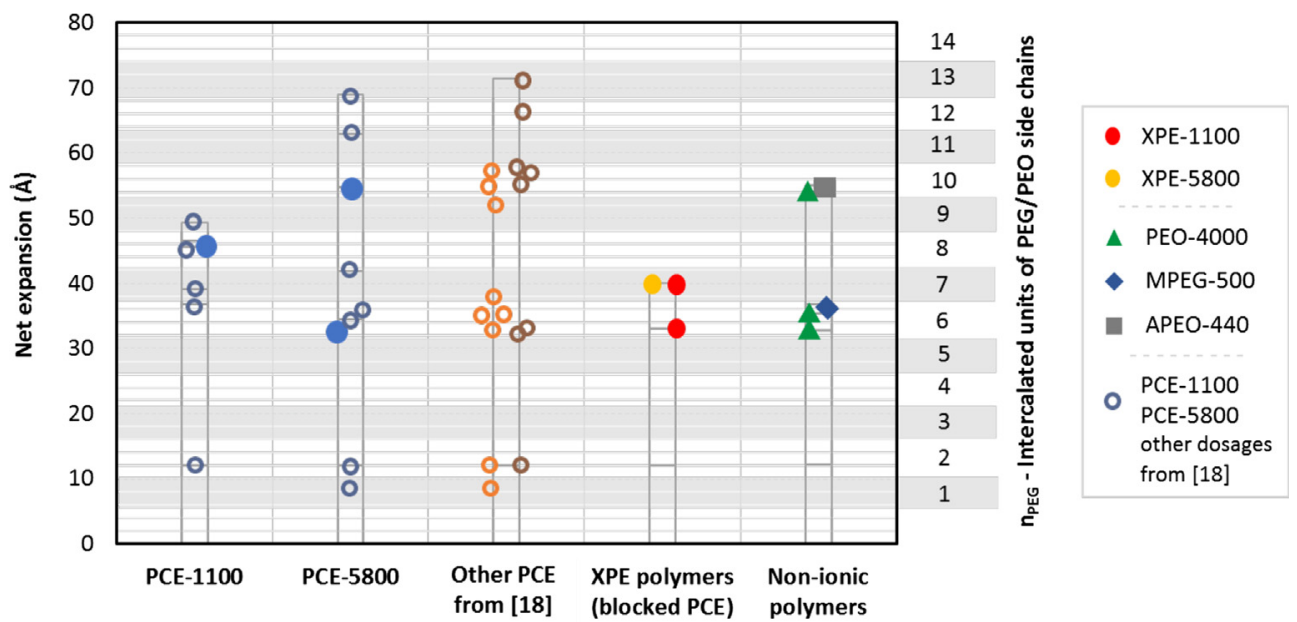

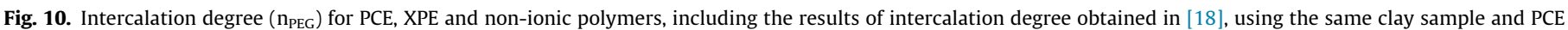
dosages of $2 \%, 5 \%, 13 \%, 50 \%, 100 \%$ and $220 \%$ by weight of clay.

layer of MNT clays $[32,39])$ and the associated intercalation degree $\left(n_{\text {PEG }}\right)$ obtained at $50 \%$ dosage are represented in Fig. 10. For the sake of completeness, Fig. 10 includes the intercalation levels from the previous work of the authors [18], for PCE-1100 and PCE-5800 at different dosages than $50 \%$ and with two polycarboxylate polymers different than PCE-1100 and PCE-5800, taking advantage of the fact that the test conditions in both works are identical.

The variations in d-spacing deduced from in situ XRPD analysis confirms that the high sorption rates observed in Fig. 8(b) for XPE and for the non-ionic polymers in clay pastes are consequence of their intercalation into Na-MNT clay, producing clay expansion. In the previous publication of the authors [18], it is deduced that there are some preferred levels of intercalation for the PCE polymers that seems to be maintained both in the case of XPE polymers and of the non-ionic polymers. It can be observed that the most common intercalation levels correspond to $\mathrm{n}_{\mathrm{PEG}}=6, \mathrm{n}_{\mathrm{PEG}}=7$ and $n_{P E G}=10$, which coincide with the preferred levels identified in [18] for the same clay sample. Therefore, taking into account the fact that preferred levels of intercalation are reproduced even with polymers of very different structure from PCE, it seems appropriate to postulate that it is the nature of the clay itself that conditions these preferred levels and not so much the type of polymer. If this finding is validated, the composition and structure of the MNT clay would acquire a relevant importance as the structure of the PCE polymer in the interference process that has been largely ignored until now.

\subsection{Absorption conformations for XPE and non-ionic polymers}

It is known that the amount of intercalated polyethylene glycol (PEG) into MNT and its arrangement depend on both the length of the polymer and on the layer charge of the clay [40-44]. In terms of adsorbed amount, it increases as the layer charge of the clay is higher, but at very high layer charge values it begins to decrease [26]. The same trend is observed in regards of the length of PEG since the adsorbed amounts increase as the longer the chain length is, but it begins to decrease from molecular weights of $100.000 \mathrm{~g} / \mathrm{mol}$ [44]. In terms of absorption conformations, the layer charge of the clay modifies the internal arrangement of the linear PEG polymers as Fig. 11 shows. From a PEG layered sequence arranged in parallel to clay plates when layer charge is low (Fig. 11 (a)), the orientation of the chains is evolving towards a perpendicular arrangement as the clay charge increases (Fig. 11(b)) until describing the pillared arrangement shown in Fig. 11(c) [41]. Nevertheless, the pillared arrangement is only affordable for short chain PEGs.

Assuming the parallel conformation illustrated in Fig. 11(a), the calculated number of intercalated chains deducted from the net expansion obtained for MPEG-500 is 6 unit-layers. This possible conformation for MPEG-500 intercalation is represented in Fig. 12(a). Nevertheless, the measured net expansion of $36.7 \AA$ is suspiciously equivalent to the length of the MPEG-500 polymer, suggesting that the intercalated units of MPEG-500 could be arranged in the pillared conformation, as represented in Fig. 12(b).

For PEO-4000, three different intercalation degrees are identified. Maximum d-spacing at $63.6 \AA$ is associated to 10 units of PEO-4000 intercalated and arranged as it is illustrated in Fig. 12 (a). The next two levels at $44.9 \AA$ and $42.3 \AA$ are so close that they are both associated to 6 units of PEO- 4000 intercalated in the same conformation. Because the estimated length of PEO-4000 is close to $300 \AA$, the pillared arrangement for this polymer is not possible. Nevertheless, the long size of PEO-4000 allows alternative arrangements such as the helical conformation represented in Fig. 12(c) or as a kind of wave-like arrangement like the one represented in Fig. 12(d) [43]. Since up to 3 different intercalation degrees are identified for PEO-4000 and two of them likely correspond to the same number of intercalated chains, it must be considered the possibility of coexistence of different absorption conformations.

Since clay charge is a key factor defining which of those conformations is taking place, it is another indicator suggesting that the characteristics of the clay are determinant in the intercalation profile and therefore for the magnitude of the interference produced in a)

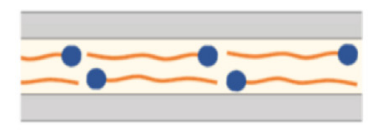

b)

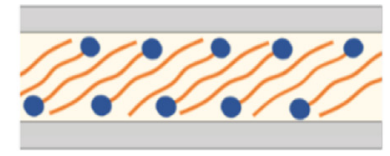

c)

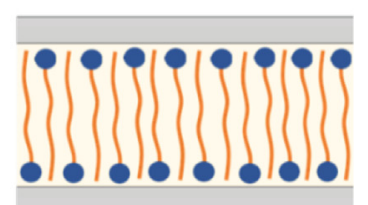

Fig. 11. Arrangement for intercalated PEG in function of layer charge of MNT clay. 

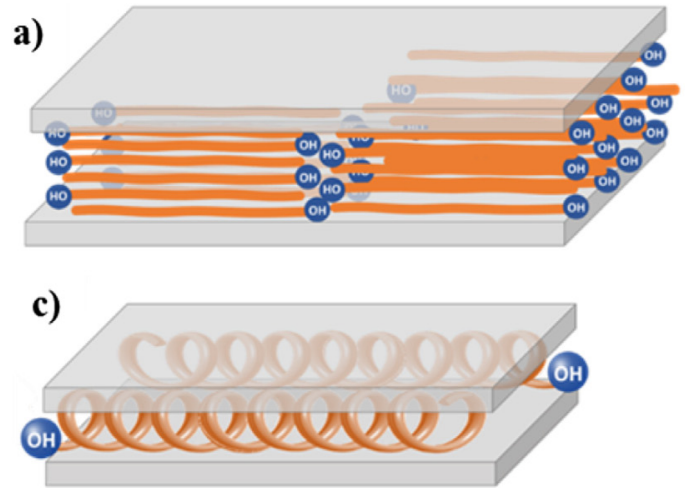

d)
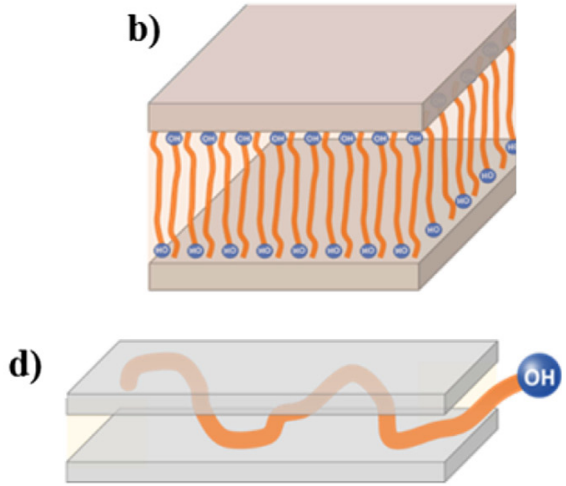

Fig. 12. Intercalation confirmations for; a) MPEG-500, PEO-4000 in overlapped layers; b) MPEG-500 pillared; c) PEO-4000 helical; d) PEO-4000 wave-like.

the fluidity of cementitious systems containing clays. Supporting this hypothesis, it is known that the arrangement taken by zwitterionic surfactants change as function of the cation exchange capacity of MNT clays [27].

One unique intercalation degree at $64.5 \AA$ interlayer d-spacing is observed for APEO-440. An arrangement based on overlapped chains parallel to clay plates is ruled out due to the highly hydrophobicity of nonylphenol terminal that cannot be exposed to the polar siloxane groups of the internal clay surface neither to the aqueous media. Therefore, the conformation taken needs to protect the nonylphenol terminals from the polar environment so only the arrangements where nonylphenol terminals remain isolated are feasible. This could be achieved by a pillared doublelayer conformation where hydrophobic groups are located in the centre of the interlaminar space, as far as possible from the internal, polar clay surface although semi-pillared or L-like double-layer conformations are also possible for APEO-440 since these arrangements are already known for molecules of similar characteristics [27].

Whatever the absorption conformation is, the fact the APEO440 is intercalated proves that the mere presence of polar linear chains is sufficient to trigger the absorption of the entire molecule. Thus, since only $10 \mathrm{EO}$ mol chains are enough to force the intercalation of an ethoxylated polymer having highly hydrophobic terminals such as APEO-440, it can be considered that side chains can be even a more determining factor than adsorption on surface so that intercalation occurs or not. This is corroborated by XPE blockedPCE polymers. XPE-1100 and XPE-5800 intercalate 6 and 7 side chains units. Therefore, the intercalation rates for both XPE are lower than those of the respective PCE polymers with equivalent side chain length. The fact that the sorption results on clay for XPE polymers are more than $60 \%$ lower than that for the PCE polymers and that XPE polymers show almost no sorption on cement, suggests that the intercalation into the interlaminar space is produced despite there is no adsorption of XPE polymer on clay surface. Thus, sorption results for XPE polymers only reflects absorbed polymer into clay. In any case, since unique intercalation degrees of XPE polymers are 6 and 7, corresponding with the preferred degrees of intercalation observed also for all polymers intercalated into the clay used, this suggests that for this type of polymers the nature of the clay may have more influence that the polymer itself in the intercalation behaviour. And in addition, the intercalation observed for XPE polymers confirms that the absorption of branched polymers having polar side chains is feasible without the need for surface adsorption. Nevertheless, the lack of polymer adsorption on clay surface leads to lower expansion so, to lower side chain intercalation degrees, in agreement with the experimental results.

\section{Interaction models between PCE polymers and Na-MNT clay}

\subsection{Absorption conformations}

Based on the conformation models and arrangements proposed for the non-ionic polymers and for the XPE esterified polycarboxylates, and considering the results of fluidity, adsorption and intercalation of PCE polymers, three models of absorption conformations in MNT are proposed in Fig. 13.

In the plugged conformation of absorption presented in Fig. 13 (a), the intercalation of side chains is produced without previous or neither simultaneous adsorption of polymer on clay surface, so side chains are directly intercalated into clay from polymer units not adsorbed (so, like plugged). Therefore, the absorption process is promoted exclusively by the direct intercalation of side chains so controlled by the affinity for being intercalated into the clay. This is the conformation arranged by XPE polymers since adsorption on clay surface is not possible because the anionic charge of PCE is temporally blocked by esterification. In the plugged conformation, it is possible that side chains from one single unit of polymer are intercalated by more than one clay particle (P-1 and P-2 in Fig. 13) if the length of the chains is long enough to keep the clay particles away and avoid electrostatic repulsion between them. The plugged conformation seems not feasible for PCE polymers owning effective anionic charge. It is deducted from the high sorption rates observed for PCE polymers, which confirms that when anionic charge is available, adsorption on clay surface is produced. Thus, the plugged conformation could only occur in the case of PCE polymers with very little anionic charge that interact with MNT clays with very little layer charge.

Fig. 13(b) corresponds to the one-to-one absorption conformation. In this case, the adsorbed units of PCE intercalate their side chains only and exclusively in the clay particle they are adsorbed on and without the possibility of sharing (intercalating) side chains into another neighbouring clay particle. It happens when PCE adsorption is concentrated in the edge surface of clay, therefore making very accessible the interlaminar spaces. Since the edge surface of MNT clays is typically very small in relation to total clay surface $[45,46]$, it is expected that edge area will become saturated very rapidly by the adsorbed PCE. Thus, the possibility to share intercalated side chains from one single PCE unit with some nearby particles having also the edge-surface saturated by PCE seems difficult due to hindrance aspects.

The one-to-one conformation is the most appropriate for MNT clays with reduced basal surface charge (so low isomorphic substitution, small CEC). In clays like this, the total layer charge is mostly located in the particle edges while basal planes are more neutral [47-50], therefore the adsorption of PCE polymer is mainly concen- 
a)

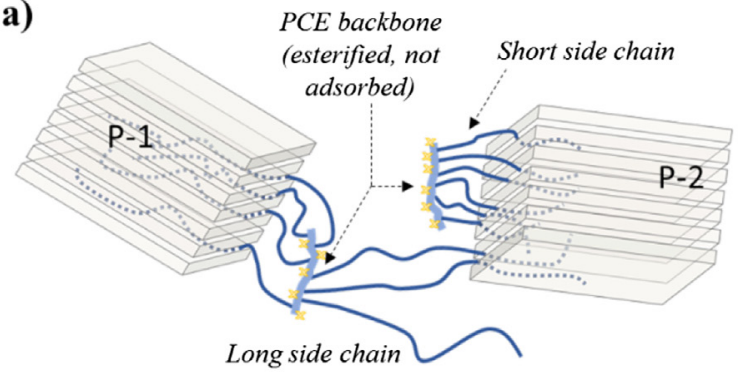

Plugged conformation

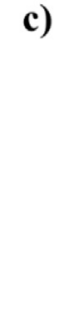

Adsorbed PCE with long side chain

c) b)

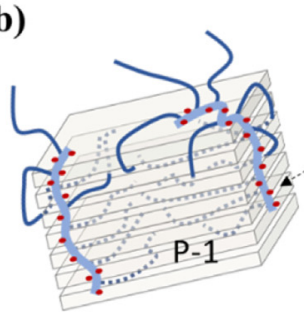

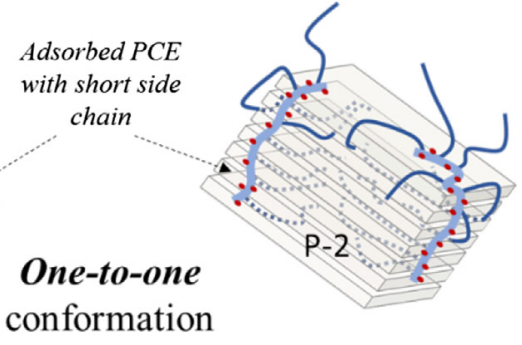

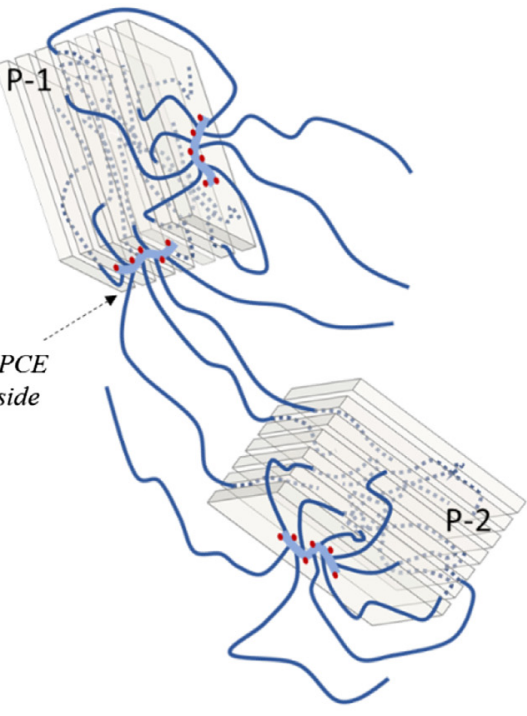

Bridging conformation

Fig. 13. Absorption conformations for PCE polymers into Na-MNT.

trated on the edge surface rather than on the basal surface. According to this hypothesis, clays having these characteristics should lead to an earlier saturation of the interlaminar space by intercalation, thus demanding low PCE dosage to reach the $\mathrm{D}_{\text {sat }}$ - saturation dosage, as defined in [18]. To a lesser extent, MNT clays with large number of stacked plates per particle are more likely to acquire one-to-one conformation simply because the increased ratio of total edge surface, providing larger number of accesses for intercalation. The one-to-one conformation is also the most appropriate for PCE polymers with short side chains because the reduced length will not allow shared intercalation of side chain from one PCE unit with other nearby clay particles, which must be too close and so subjected to electrostatic repulsion.

In the bridging conformation depicted in Fig. 13(c), adsorption on clay surface and shared intercalation with neighbouring clay particles ( $\mathrm{P}-1$ and $\mathrm{P}-2$ ) are produced at the same time. The bridging conformation is the preferred one when MNT has high basal surface charge and large aspect ratio. In these conditions, PCE units are adsorbed in both basal and edge surface of clay. Due to the morphology of clay particles, basal surface is much larger than edge surface and far more accessible to adsorption. Thus, it can be considered that adsorption on basal surface will be preferred in clays such as these. PCE units adsorbed on basal surface can be intercalated only if side chains are long enough to reach the interlayer openings located at the particle edges [18]. Otherwise, the intercalation in the same particle (P-1) is not feasible. In this case, the free-oriented side chains of the PCE unit adsorbed on the basal surface of one clay particle can be intercalated by neighbouring particles (P-2) because the occupation is mainly concentrated in the basal surfaces and, consequently, the edge surfaces remain accessible for intercalation. From the polymer perspective, PCE polymers having large side chains and high side chain density acquire bridging conformation due to the high steric repulsion that prevents all the side chains belonging to one single PCE from being intercalated within the same clay particle on which it is adsorbed.

\subsection{Promoters of intercalation}

From the previous section, it can be deduced that the absorption conformation to be acquired is controlled by: i) clay proper- ties such as layer charge by isomorphic substitution and, to a lesser degree, by the particle morphology (number of stacked plates, aspect ratio); and ii) PCE polymer properties such as the length and density of side chains. Surprisingly, PCE anionic charge seems to be of little relevance in the definition of the conformation models, but as it was reported in the previous work of the authors [18], the anionic charge of the polymer defines the saturation dosage $\left(D_{\text {sat }}\right)$ at the time when the interlaminar space of MNT clay is almost fully intercalated by side chains (so, saturated). Therefore, it can be stated that while the absorption conformation is determined by the factors previously mentioned, the anionic charge of PCE polymer determines the efficiency of the intercalation.

To determine the contribution of PCE anionic charge in the evolution of total sorption rate of polymer on MNT pastes, the sorption isotherms on Na-MNT clay for PCE and XPE polymers, PMA linear polymethacrylate and for the non-ionic polymers are presented in Fig. 14.

The profile of the isotherms shown in Fig. 14 for PCE polymers confirms that, when the polymer has anionic charge, the sorption evolves more efficiently than any polymer without an effective charge. Apart from PMA that is not absorbed/intercalated, and hence its rapid saturation at the lowest levels of uptake, all other polymers base their measured sorption mainly on the intercalation into MNT, and only PCE polymers experience simultaneously adsorption on clay surface and absorption by intercalation. Nevertheless, from the sorption saturation levels of PMA in comparison with that for PCE, it can be inferred that most of the sorbed amount measured for PCE polymers is likely due to intercalation and not to surface adsorption.

XPE esterified polycarboxylates, in agreement with the proposed plugged conformation of absorption, present the most reduced affinity for intercalation since both XPE-1100 and XPE5800 stabilize its sorption rate at the lowest dosage within all polymers, on total sorbed amounts being $60-70 \%$ lower that of PCE polymers. Sorption evolution of polyglycols MPEG-500 and PEO4000 (so absorption by intercalation since, as seen in Fig. 8(a) with cement, they are not surface sorbed) evolves more progressively than PCE polymers and its saturation is not observed within the range of dosages tested. 


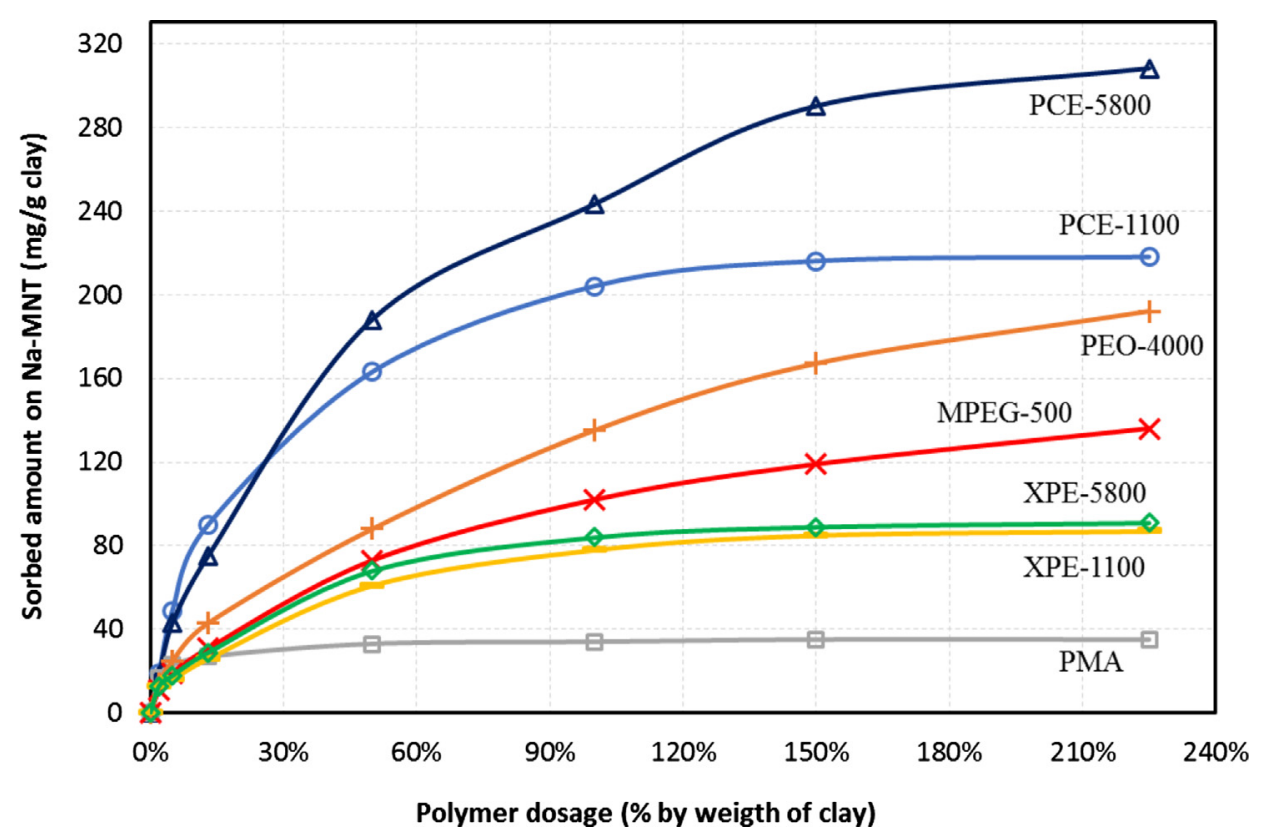

Fig. 14. Sorption isotherms on Na-MNT of the studied polymers.

Finally, sorption of PCE polymers at low dosage evolves much efficiently than any other polymer and the stabilization is reached at the highest amounts of sorption. Therefore, it denotes that the anionic charge promotes a more efficient intercalation into MNT clay and it is the determining factor that allows the intercalation of a large number of side chains in a reduced space, overcoming part of the steric hindrances that would not allow such grouping of chains under normal conditions, as shown by the sorption isotherms of the other polymers not having anionic charge.

For PCE-5800 it is expected the bridging conformation because its long side chains. For this conformation, it can be deduced that the total sorption progresses faster than the intercalation degree since the intercalation of side chains from the adsorbed units of PCE is shared with other clay particles. Therefore, there is no massive, punctual intercalation. Conversely, PCE-1100 having shorter side chains is expected to arrange in the one-to-one conformation. In this conformation, supported by the higher anionic charge of this PCE, the intercalation degree and the polymer sorption progress more smoothly because the intercalation is concentrated on the same clay particle where the polymers units are adsorbed on, thus creating large intercalation but only in local sites of the clay particle. This is evident for the two PCE polymers by comparing the evolution of the interlayer d-spacing presented in Fig. 4 with the sorption isotherms displayed in Fig. 14.

According to the previous reasoning, when bridging conformation is taken place, it is expected that clay particles with high intercalation degrees coexist with particles with lower intercalation degrees as consequence of a more random process. Conversely, for the one-to-one conformation, most of the clay particles would have similar, homogeneous degree of intercalation. This is confirmed by the intensity of Peak 3 in the XRPD patterns of PCE1100 and PCE-5800 displayed in Fig. 3. It can be observed that Peak 3 at $18.3 \AA$ (corresponding to $n_{\text {PEG }}=1$ ) for PCE-5800 is always visible and of high intensity, coexisting with Peak 1 . Therefore, different clay specimens with different intercalation degree are present at the same time. For PCE-1100, Peak 3 disappears at the first addition of PCE and it does not appear until the highest dosage of PCE1100 is added, thus only a unique intercalation degree is observed at almost all dosages tested. The same affirmation works to understand why PCE-5800 having higher side chain density and longer side chains than PCE-1100 experiences lower absolute reduction of paste flow in the flocculation phase of clay pastes presented in Fig. 2(b), but the dosage range where flocculation is produced is larger than that of PCE-1100.

\section{Conclusions}

PCE polymers intercalated into MNT can be arranged preferably in two possible absorption conformations: one-to-one conformation and bridging conformation. A third model described, plugged conformation, seems to be not appropriate to polymers having anionic charge and it would be possible only for very particular cases. The preferred conformation for PCE absorption is dictated by key properties of the polymer(s) and the clay(s). For the polymer, the two main characteristics are the length of side chains and the side chain density. For the MNT, the mains properties are the layer charge and to a lesser extent the morphology of the clay particle. PCE anionic charge is a key factor for the earlier saturation but not for the absorption arrangement.

The models of adsorption conformation proposed allow a reasonable and consistent explanation about the interaction processes between PCE polymers and MNT that fits the experimental results. But at the same time, also highlight the importance of the properties of clay for the understanding of the intercalation arrangements. Therefore, in any experimental work where PCE-MNT interaction is studied, it is needed to specify as much as possible the properties of the clay used otherwise the comparison of results from different studies is not feasible.

\section{Declaration of Competing Interest}

The authors declare that they have no known competing financial interests or personal relationships that could have appeared to influence the work reported in this paper.

\section{Acknowledgments}

Mr. Borralleras thanks all the support given by BASF Construction Chemicals to the development of this work. Dr. I. Segura is supported by the postdoctoral Torres Quevedo program of the Spanish Ministry of Economy and Competitiveness. 


\section{References}

[1] E. Sakai, A. Ishida, A. Ohta, New trends in the development of chemical admixtures in Japan, Proc. J. Adv. Concr. Technol. 4 (2006) 211-223.

[2] F. Puertas, H. Santos, M. Palacios, S. Martínez-Ramírez, Polycarboxylate superplasticizers admixtures: effect on hydration, microstructure and rheological behaviour in cement pastes, Adv. Cem. Res. 17 (2005) 77-89.

[3] P.C. Aïtcin, R.J. Flatt, Science and technology of concrete admixtures, ISBN 9780-08-100693-1 (2016).

[4] J. Plank, C. Schroefl, M. Gruber, M. Lesti, R. Sieber, Effectiveness of polycarboxylate superplasticizers in ulta-high strength concrete: the importance of PCE compatibility with silica fume, J. Adv. Concr. Technol. 7 (2009) 5-12.

[5] D. Atarashi, Interaction between superplasticizers and clay minerals, Jpn. Cem. Assoc. (2005) 287-292.

[6] D. Atarashi, K. Yamada, A. Ito, M. Miyauchi, E. Sakai, Interaction between montmorillonite and chemical admixture, J. Adv. Concr. Technol. 13 (2015) 325-331.

[7] L. Xoing, G. Zheng, Y. Bi, C. Fu, Effect of typical clay upon the dispersion performance of polycarboxylate superplasticizer, in: Proceedings International Conference on Materials, Environmental and Biological Engineering, 2015, pp. 226-229.

[8] L. Lei, J. Plank, A study on the impact of different clay minerals on the dispersing force of conventional and modified vinyl ether based polycarboxylate superplasticizers, Cem. Concr. Res. 60 (2014) 1-10.

[9] S. Qian, H. Jiang, B. Ding, Y. Wang, C. Zheng, Z. Guo, Synthesis and performance of polycarboxylate superplasticizer with clay-inerting and high slump retention capability, Mater. Sci. Eng. 182 (2017).

[10] X. Shu, Q. Ran, J. Liu, H. Zhao, Q. Zhang, X. Wang, Y. Yang, Tailoring the solution conformation of polycarboxylate superplasticizer toward the improvement of dispersing performance in cement paste, Constr. Build. Mater. 116 (2016) 289298.

[11] L. Lei, J. Plank, Synthesis and properties of a vinyl ether-based polycarboxylate superplasticizer for concrete possessing clay tolerance, Ind. Eng. Chem. Res. 53 (2014) 1048-1055.

[12] H. Tan, M. Xin Li, B. Liu, B. Ma, X. Li Gu, Tolerance of cement for clay minerals: effect of side-chain density in polyethylene oxide (PEO) superplasticizers additives, Clay Clay Miner. 64-6 (2016) 732-742.

[13] H. Tan, B. Gu, B. Ma, X. Li, C. Lin, Mechanism of intercalation of polycarboxylate superplasticizer into montmorillonite, Appl. Clay Sci. 129 (2016) 40-46.

[14] S. Ng, J. Plank, Interaction mechanisms between Na-montmorillonite clay and MPEG-based polycarboxylate superplasticizers, Cem. Concr. Res. 42 (2012) $847-854$.

[15] G. Xing, W. Wang, G. Fang, Cement dispersion performance of superplasticizers in the presence of clay and interaction between superplasticizers and clay, Adv. Cem. Res. 29 (2017) 194-205.

[16] H. Tan, B. Gu, Y. Guo, B. Ma, J. Huang, J. Ren, F. Zou, Improvement in compatibility of polycarboxylate superplasticizers with poor-quality aggregate conatining montmorillonite by incorporating polymeric ferric sulfate, Constr. Build. Mater. 162 (2018) 566-575.

[17] P. Borralleras, I. Segura, M.A.G. Aranda, A. Aguado, Influence of experimental procedure on d-spacing measurement by XRD of montmorillonite clay pastes containing PCE based superplasticizer, Cem. Concr. Res. 116 (2019) 266-272, https://doi.org/10.1016/j.cemconres.2018.11.015.

[18] P. Borralleras, I. Segura, M.A.G. Aranda, A. Aguado, Influence of polymer structure of polycarboxylate based superplasticizers in the intercalation mechanism in montmorillonite clay, Cem. Concr. Compos. (under review).

[19] R. Magarotto, I. Torresan, Zeminian N. Effect of alkaline sulphates on the performance of superplasticizers, in: 11th International Congress on the Chemistry of Cement, 2003, pp. 569-579.

[20] D. Wilinski, P. Lukowski, G. Rokicki, Polymeric superplasticizers based on polycarboxylates for ready-mixed concrete: current state of the art, Polimery 61 (2016) 474-481.

[21] R. Qianping, X. Wang, X. Shu, J. Liu, Effects of sequence structure of polycarboxylate superplasticizers on the dispersion behavior of cement paste, J. Dispersion Sci. Technol. 37 (2016) 431-441.

[22] Y. Zhang, X. Kong, Correlations of the dispersing capability of NSF and PCE types of superplasticizer and their impacts on the cement hydration with the adsorption in fresh cement pastes, Cem. Concr. Res. 69 (2015) 1-9.

[23] G. Xing, W. Wang, J. Xu, Grafting tertiary amine groups into the molecular structures of polycarboxylate superplasticizers lowers their clay sensitivity, RSC Adv. 6 (2016) 106921-106927.

[24] L. Lei, J. Plank, A concept for a polycarboxylate superplasticizer possessing enhanced clay tolerance, Cem. Concr. Res. 42 (2012) 1299-1306.
[25] M. Matusewicz, K. Pirkkalainen, J.P. Suuronen, A. Root, A. Muurinen, R. Serimaa, M. Olin, Microstrcutural investigation of calcium montmorillonite, Clay Miner. 48 (2013) 267-276.

[26] J. Bujdak, E. Hackett, E.P. Giannelis, Effect of layer charge on the intercalation of polyethylene oxide in layered silicates: implications on nanocomposite polymer electrolytes, Chem. Mater. 12 (2000) 2168-2174.

[27] J. Zhu, P. Zhang, Y. Qing, K. Wen, X. Su, L. Ma, J. Wei, H. Liu, H. He, Y. Xi, Novel intercalation mechanism of zwitterionic surfactant modified montmorillonites, Appl. Clay Sci. 141 (2017) 265-271.

[28] R.L. Parfitt, D.J. Greenland, Adsorption of water by montmorillonite-poly (ethylene glycol) adsorption products, Clay Miner. 8 (1970) 317-324.

[29] A. Meunier, Why are clay minerals small?, Clay Miner 41 (2006) 551-566.

[30] R. Tettenhorst, H.E. Roberson, X-Ray diffraction aspects of montmorillonite, Am. Mineral. 58 (1973) 73-80.

[31] R.F. Geise, The electrostatic interlayer forces of layer structure minerals, Clay Clay Miner. 26 (1978) 51-57.

[32] E.C. Jonas, R.M. Oliver, Size and shape of montmorillonite crystallites, Clay Clay Miner. 15 (1967) 27-33.

[33] R. Oianping, X. Shu, Y. Yang, J. Zhang, Effect of molecular weight of polycarboxylate superplasticizer on its dispersion, adsorption and hydration of a cementitious system, J. Mater. Civ. Eng. 28 (2016) 184-188.

[34] H. Feng, L. Pan, Q. Zheng, J. Li, N. Xu, S. Pang, Effects of molecular structure of polycarboxylate superplasticizers on their dispersion and adsorption behaviour in cement paste with two kinds of stone powder, Constr. Build. Mater. 170 (2018) 182-192.

[35] C.Z. Li, N.Q. Feng, Y.D. Li, R.J. Chen, Effects of polyethylene oxide chains on the performance of polycarboxylate-type water-reducers, Cem. Concr. Res. 35 (2005) 867-873.

[36] J. Liu, Q. Ran, C. Miao, M. Qiao, Effects of grafting densities of comb-like copolymer on the dispersion properties of concentrated cement suspensions, Mater. Trans. 53 (2012) 553-558.

[37] H. Lombois-Burger, P. Colombet, J. Halary, H. Van Damme, On the frictional contribution to the viscosity of cement and silica pastes in the presence of adsorbing and non-adsorbing polymers, Cem. Concr. Res. 38 (2008) 13061314.

[38] H. Bessaies-Bey, R. Baumann, M. Schmitz, M. Radler, N. Roussel, Effect of polyacrylamide on rheology of fresh cement pastes, Cem. Concr. Res. 76 (2015) 98-106.

[39] M.J. Wilson, Sheet Silicates: Clay Minerals, second ed., The Geological Society Publishing House, 2013. ISBN 978-1-86239-359-2.

[40] S. Zhu, H. Peng, J. Chen, H. Li, Y. Cao, Y. Yang, Z. Feng, Intercalation behavior of poly(ethylene glycol) in organically modified montmorillonite, Appl. Surf. Sci. 276 (2013) 502-511.

[41] T. Okada, Y. Seki, M. Ogawa, Designed nanostructures of clay for controlled adsorption of organic compounds, J. Nanosci. Nanotechnol. 14 (2014) 21212134.

[42] R.W.A. Franco, C.A. Brasil, G.L. Mantovani, E.R. de Azevedo, T.J. Bonagamba, Molecular dynamics of poly(ethylene glycol) intercalated in clay, studied using ${ }^{13} \mathrm{C}$ solid-state NMR, Materials 6 (2013) 47-64.

[43] M.X. Reinholdt, R.J. Kirkpatrick, T.J. Pinnavala, Montmorillonite-poly(ethylene glycol) nanocomposites: interlayer alkali metal behavior, J. Phys. Chem. 109 (2005) 16296-16303.

[44] A. Kobayashi, M. Kawaguchi, T. Kato, A. Takahashi, Intercalation adsorption of poly(ethylene oxide) into montmorillonite, Kyoto Univ. - Bull. Inst. Chem. Res. 66 (1989) 176-183.

[45] P.H. Nadeau, The physical dimensions of fundamental clay particles, Clay Miner. 20 (1985) 499-514.

[46] A. Kahn, Studies on the size and shape of clay particles in aqueous suspension, Clays Clay Miner. 6 (1959) 220-236.

[47] H. Zhao, S. Bhattarcharjee, R. Chow, D. Wallace, J.H. Masliyah, Z. Xu, Probing surface charge potentials of clay basal planes and edges by direct force measurements, Langmuir 24 (2008) 12899-12910.

[48] T. Preocanin, A. Abdelmonem, G. Montavon, J. Luetzenkirchen, Charging behavior of clays and clay minerals in aqueous electrolyte solutions. Experimental methods for measuring the charge and interpreting the results, Clay Clay Miner. (2016). ISBN 978-953-51-2259-3.

[49] X. Liu, X. Lu, M. Sprik, J. Cheng, E.J. Meijer, R. Wang, Acidity of edge surface sites of montmorillonite and kaolinite, Geochim. Cosmochim. Acta 117 (2013) 180190.

[50] E. Tombácz, M. Szekeres, Surface charge heterogeneity of kaolinite in aqueous suspension in comparison with montmorillonite, Appl. Clay Sci. 34 (2006) 105-124. 